\title{
Moderate- to high intensity aerobic and resistance exercise reduces peripheral blood regulatory cell populations in older adults with rheumatoid arthritis
}

Sofia E. M. Andersson ${ }^{1 *}$ (D) Elvira Lange ${ }^{2,3}$, Daniel Kucharski ${ }^{1}$, Sara Svedlund ${ }^{4}$, Karin Önnheim ${ }^{1}$, Maria Bergquist ${ }^{5}$, Elisabet Josefsson ${ }^{1}$, Janet M. Lord ${ }^{6}$, Inga-Lill Mårtensson ${ }^{1}$, Kaisa Mannerkorpi ${ }^{2,3}$ and Inger Gjertsson ${ }^{1,2}$

\begin{abstract}
Objective: Exercise can improve immune health and is beneficial for physical function in patients with rheumatoid arthritis (RA), but the immunological mechanisms are largely unknown. We evaluated the effect of moderate- to high intensity exercise with person-centred guidance on cells of the immune system, with focus on regulatory cell populations, in older adults with RA.

Methods: Older adults ( $\geq 65$ years) with RA were randomized to either 20-weeks of moderate - to high intensity aerobic and resistance exercise $(n=24)$ or to an active control group performing home-based exercise of light intensity $(n=25)$. Aerobic capacity, muscle strength, DAS28 and CRP were evaluated. Blood samples were collected at baseline and after 20 weeks. The frequency of immune cells defined as adaptive regulatory populations, CD4 + Foxp3 + CD25 + CD127- T regulatory cells (Tregs) and CD19 + CD24hiCD38hi B regulatory cells (Bregs) as well as HLA-DR-/lowCD33 + CD11b + myeloid derived suppressor cells (MDSCs), were assessed using flow cytometry.
\end{abstract}

Results: After 20 weeks of moderate- to high intensity exercise, aerobic capacity and muscle strength were significantly improved but there were no significant changes in Disease Activity Score 28 (DAS28) or CRP. The frequency of Tregs and Bregs decreased significantly in the intervention group, but not in the active control group. The exercise intervention had no effect on MDSCs. The reduction in regulatory $T$ cells in the intervention group was most pronounced in the female patients.

Conclusion: Moderate- to high intensity exercise in older adults with RA led to a decreased proportion of Tregs and Bregs, but that was not associated with increased disease activity or increased inflammation.

Trial registration: Improved Ability to Cope With Everyday Life Through a Person-centered Training Program in Elderly Patients With Rheumatoid Arthritis - PEP-walk Study, NCT02397798. Registered at ClinicalTrials.gov March 19, 2015.

Keywords: Rheumatoid arthritis, Aging, Exercise, Treg cells, T cells, Breg cells, IL-10

\footnotetext{
* Correspondence: sofia.andersson@rheuma.gu.se

'Department of Rheumatology and Inflammation research, Institute of

Medicine, The Sahlgrenska Academy, University of Gothenburg, Box 480, 405

30 Göteborg, Sweden

Full list of author information is available at the end of the article
}

\section{$\triangle B M C$}

(c) The Author(s). 2020 Open Access This article is licensed under a Creative Commons Attribution 4.0 International License, which permits use, sharing, adaptation, distribution and reproduction in any medium or format, as long as you give appropriate credit to the original author(s) and the source, provide a link to the Creative Commons licence, and indicate if changes were made. The images or other third party material in this article are included in the article's Creative Commons licence, unless indicated otherwise in a credit line to the material. If material is not included in the article's Creative Commons licence and your intended use is not permitted by statutory regulation or exceeds the permitted use, you will need to obtain permission directly from the copyright holder. To view a copy of this licence, visit http://creativecommons.org/licenses/by/4.0/ The Creative Commons Public Domain Dedication waiver (http://creativecommons.org/publicdomain/zero/1.0/) applies to the data made available in this article, unless otherwise stated in a credit line to the data. 


\section{Background}

Rheumatoid arthritis (RA) is an autoimmune joint disease driven by complex immune dysregulation and which may have a profound impact on healthy aging. Having RA accelerates aging [1] and age-related changes in the immune system are believed to increase the risk for autoimmune disease, infections and cancer development [2]. Animal studies suggest that regulatory $\mathrm{T}$ cells (Tregs) are less efficient in dampening autoimmune pro-inflammatory responses with age but are on the other hand more prone to cause erroneous protection of cancer cells [3, 4] and allow reactivation of chronic viral infections [5]. With age, Treg frequency is increased in blood and tissues, however it is less clear whether the Tregs function is altered $[3,6]$. Patients with RA seemingly have a reduced frequency of Tregs (Foxp3 + CD25+) in peripheral blood compared to healthy individuals, and a higher frequency in synovial fluid compared to peripheral blood [7]. Regulatory CD24hiCD38hi B cells (Bregs) are reduced in patients with active RA [8] and both frequency of Bregs as well as their IL10 production decline with age [9]. Myeloid-derived suppressor cells (MDSCs) are a heterogeneous population of myeloid derived cells at an early stage of development that exhibits immunosuppressive properties and they increase in peripheral blood with age [10] and during chronic inflammatory conditions, such as autoimmune diseases and cancer [11].

Exercise has a revitalizing effect on the aging immune system and promotes healthy immune function, for example it improves the response to vaccines [12], without aggravating autoimmune responses [13]. It promotes acute release of anti-inflammatory myokines from skeletal muscle and causes reduction of visceral fat releasing pro-inflammatory adipokines [13, 14] thereby it reduces the chronic low-grade inflammation known as inflamm-aging [12]. We have shown that older adults ( $\geq 65$ years) with RA improve significantly with respect to aerobic capacity and muscle strength, fatigue and patient's global impression of change (PGIC) $[15,16]$ after 20 weeks of moderate- to high intensity aerobic and resistance exercise with personcentred guidance [15].

However, it is not currently known if moderate- to high intensity exercise in older adults with RA will have an effect on immune regulation. This study aimed to evaluate the effects of a 20 weeks moderate- to high intensity, aerobic and resistance exercise intervention with person-centred guidance on regulatory immune cell populations in patients with $\mathrm{RA} \geq 65$ years of age. We hypothesized that moderate- to high intensity exercise would influence regulatory immune cell subsets in peripheral blood of older adults with RA.

\section{Methods}

\section{Participants}

This randomized controlled study contains data from the Gothenburg-cohort comprising 49 patients recruited at Sahlgrenska University Hospital, Gothenburg. The Gothenburg-cohort is a subset of a total of 74 patients included in the Pep-walk study [15]. The inclusion criteria were patients diagnosed with RA according to the ACR 1987/EULAR 2010 criteria, age $\geq 65$ years, disease duration $\geq 2$ years and DAS28 score $<5.1$. The exclusion criteria were other significant comorbidity such as unstable coronary heart disease or dysregulated cardiac arrhythmia that precludes moderate to intense exercise, joint surgery within 6 months prior to inclusion, already on-going exercise on moderate to high level $\geq 2$ times week, other factors that would influence the participation such as residence far from site or insufficient communicative abilities. All patients were recruited in 2015 and the samples were collected during 2015 and 2016. Out of the 49 patients recruited at Sahlgrenska University Hospital, Gothenburg, 48 patients completed the study [15]. Patient characteristics are shown in Table 1. Clinical data for all patients $(n=74)$ together is published by Lange et al. [15].

\section{Randomization}

We used stratified randomization with sex as a stratifying variable. A person not involved in intervention or examination conducted the randomization using sealed opaque envelopes and a computer generated sequence of allocation into one of two groups, exercise or control [15].

\section{Intervention}

The exercise intervention group $(n=24)$ followed an exercise protocol of gym-based resistance and aerobic exercise performed at moderate- to high intensity (defined as $70-89 \%$ of maximum heart rate and $70-80 \%$ of 1 repetition maximum) 3 times a week, with personcentred guidance from physiotherapist. Both the intervention group and the active control group $(n=25)$ were encouraged to perform low-intensity daily physical activity plus home-based exercises for mobility, strength and balance without any weights or equipment 2 times a week. The exercise protocols and the person-centred approach are described in detail in Lange et al. 2019 [15].

\section{Maximal oxygen consumption measurement}

Maximal oxygen consumption - $\mathrm{VO}_{2}$ max was measured by cardiopulmonary exercise testing (CPET). Oxygen content of expired gas was measured during a bicycle ergometer test, using a metabolic chamber (OxyCon, Jaeger, Sollentuna, Sweden) and the maximal oxygen 
Table 1 Baseline demographics and clinical characteristics of participants

\begin{tabular}{|c|c|c|c|}
\hline & Control $(\boldsymbol{n}=25)$ & Exercise $(\boldsymbol{n}=24)$ & $p$-value \\
\hline Female, n (\%) & $21(84 \%)$ & 19 (79\%) & 0.73 \\
\hline Mean age (years) $\pm S D$ & $70 \pm 2.4$ & $69 \pm 2.7$ & 0.17 \\
\hline Disease duration, median $\pm I Q R$ & $20(11-24)$ & $13(9.3-19)$ & 0.06 \\
\hline HAQ-DI, median \pm IQR & $0.50(0.25-0.94)$ & $0.19(0.0-0.84)$ & 0.06 \\
\hline ESR, median $\pm I Q R$ & $10(7.0-17.5)$ & $11(4.3-20.8)$ & 0.69 \\
\hline $\mathrm{CRP}$, median $\pm \mathrm{IQR}$ & $2(1-5)$ & $3(1-3)$ & 0.58 \\
\hline DAS28, median \pm IQR & $2.3(1.6-3.3)$ & $2.2(1.2-3.2)$ & 0.78 \\
\hline $\mathrm{ACPA}+$ & $16(64 \%)$ & $20(83 \%)$ & 0.20 \\
\hline $\mathrm{RF}+$ & $20(80 \%)$ & $19(79 \%)$ & $>0.99$ \\
\hline DMARDs & $18(72 \%)$ & $22(92 \%)$ & 0.14 \\
\hline Methotrexate & $15(60 \%)$ & $21(88 \%)$ & 0.0507 \\
\hline Methotrexate (dose), median + IQR & $15(12.5-20)$ & $20(15-25)$ & 0.10 \\
\hline Biologics & $12(48 \%)$ & $9(38 \%)$ & 0.57 \\
\hline TNF inhibitors & $6(24 \%)$ & $8(33 \%)$ & 0.54 \\
\hline Rituximab & $3(12 \%)$ & $1(4 \%)$ & 0.61 \\
\hline NSAIDs & $17(68 \%)$ & $13(54 \%)$ & 0.39 \\
\hline Corticosteroid use & $3(12 \%)$ & $1(4 \%)$ & 0.61 \\
\hline Cardiovascular diseases & $5(20 \%)$ & $5(21 \%)$ & $>0.99$ \\
\hline Previous malignancy & $4(16 \%)$ & $8(33 \%)$ & 0.20 \\
\hline Lung disease & $1(4 \%)$ & $1(4 \%)$ & $>0.99$ \\
\hline Never-smokers & $9(36 \%)$ & $10(42 \%)$ & 0.77 \\
\hline Smokers & $2(8 \%)$ & $1(4 \%)$ & $>0.99$ \\
\hline Ex-smokers & $14(56 \%)$ & $13(54 \%)$ & $>0.99$ \\
\hline
\end{tabular}

Table I show values at baseline. Statistical analyses were performed using the Fisher's exact test or the Mann-Whitney U-test

consumption per minute and $\mathrm{kg}$ body weight (relative $\left.\mathrm{VO}_{2} \max \right)$ was calculated $\left(\mathrm{mlO}_{2} / \mathrm{min} / \mathrm{kg}\right)$.

\section{Clinical assessment and disease activity}

All patients were examined by a physician and a physiotherapist at baseline and after 20 weeks. The examiners were blinded to group allocation. Height, weight and blood pressure were measured. Disease activity was determined by the composite scores disease activity score 28 (DAS28) and clinical disease activity index (CDAI). Disability was determined by the Health Assessment Questionnaire - Disability Index (HAQ-DI). Dynamic leg muscle strength was assessed using the Sit To Stand (STS) test [15]. At the end of the study, patients rated their change of health since the study start on the $\mathrm{Pa}$ tient Global impression of Change (PGIC) scale ranging from 1 (very much improved) to 7 (very much worse). The clinical variables are previously reported in [15].

\section{Collection of blood samples}

At baseline and 20 weeks, peripheral blood was collected from the participants between 8 and $12 \mathrm{am}$. The 20week sampling was collected at least $24 \mathrm{~h}$ after the last exercise session. $C$ reactive protein (CRP) was analysed by the routine Clinical Chemistry lab, Sahlgrenska University Hospital, Gothenburg, Sweden.

\section{Isolation of peripheral blood mononuclear cells (PBMCs) and plasma}

The blood cells were counted on a KX-21 N ${ }^{\mathrm{m}}$ Automated Hematology Analyzer (Sysmex) and centrifuged at $800 \mathrm{x}$ $\mathrm{g}$ for $10 \mathrm{~min}$. Plasma was transferred to cryotubes and stored at -80 degrees until analysis. PBMC were isolated using SepMate tubes (STEMCELL Technologies) and stored at - 150 degrees in FCS with 10\% DMSO.

\section{Phenotypic characterization using flow cytometry}

Thawed PBMC were washed in FACS buffer (PBS, 10\% heat inactivated FBS, $1 \mathrm{mM}$ EDTA) and blocked in FACS buffer with $0.5 \%$ mouse serum. Antibodies used in this study are listed in (Additional file 1). Intracellular staining was performed using the Foxp3 Transcription Factor Staining Buffer Set (eBioscience). Cell samples from one individual pre and post exercise were thawed and stained at the same time and acquired using the same flow cytometric settings on a BD FACSVerse ${ }^{\mathrm{rm}}$. 
Gating strategies are shown for Tregs in (Fig. 2a-c), Bregs and MDSCs in (Additional file 2). All phenotypic characterizations were performed using FlowJo version 9.9.4. (Tree Star, Ashland, Oregon). Identical gates were set for every patient sample pair (pre and post exercise). The absolute number of Tregs was calculated by multiplying the frequency of Tregs contained within the lymphocyte gate by the number of lymphocytes per $\mathrm{ml}$ blood, that was determined in whole blood before PBMC isolation using a a KX-21 N $\mathrm{N}^{\mathrm{sm}}$ Automated Hematology Analyzer (Sysmex).

\section{Determination of myokines in plasma}

Myokines, including IL-10, were measured using a ProcartaPlex Human Myokine Panel (lot: 117980001, 121, 573,002 , eBioscience). Limits of quantification were set by the manufacturer as follows: IL-10 $(1.94 \mathrm{pg} / \mathrm{ml})$, BDNF $(1.35 \mathrm{pg} / \mathrm{ml}), \operatorname{LIF}(5.74 \mathrm{pg} / \mathrm{ml})$, TNF $\alpha(8.03 \mathrm{pg} / \mathrm{ml})$, IL-8 $(2.47 \mathrm{pg} / \mathrm{ml})$, IL-1RA $(33 \mathrm{pg} / \mathrm{ml}), \mathrm{IL}-15(2.31 \mathrm{pg} / \mathrm{ml})$, IL-6 $(9.99 \mathrm{pg} / \mathrm{ml})$. The samples were read on a Bio-Plex ${ }^{\circ}$ 200 array reader (Bio-rad). IGF-1 was measured using a human IGF-1 duoset ELISA with plasma samples diluted 1:30 (R\&D systems, detection limit $31 \mathrm{pg} / \mathrm{mL}$ ). Concentrations below the detection limit and to low to be extrapolated were assigned a value of $0 \mathrm{pg} / \mathrm{ml}$.

\section{T cell proliferation assay}

Thawed PBMC were washed in cell culture medium. $\mathrm{CD} 4+\mathrm{T}$ cells were isolated using negative isolation with Antibody Mix Human CD4 and depletion MyOne beads from Dynabeads ${ }^{\circ}$ Regulatory CD $4+$ CD25+ T Cell Kit (Dynabeads). Cells were stained using CellTrace violet cell proliferation kit (Invitrogen) at a working concentration of $1.25 \mu \mathrm{M}$ and a cell concentration of $1 \times 10^{6}$ cells $/ \mathrm{ml}$. CD4+ T cells were seeded at $1 \times 10^{5}$ cells/well in a 96-well round bottom plate pre-coated with $1,5 \mu \mathrm{g} / \mathrm{ml}$ mouse anti-human CD3e (clone: OKT3, Invitrogen) in Complete medium (RPMI 1640 GlutaMAX, with 10\% FCS, Non-Essential Amino Acids, $1 \mathrm{mM}$ Sodium pyruvate, $50 \mu \mathrm{M} \beta$-mercaptoethanol, $100 \mathrm{U} / \mathrm{ml}$ PenicillinStreptomycin (all from GIBCO)), with $1 \mu \mathrm{g} / \mathrm{ml}$ of mouse anti-human CD28 (clone: CD28.2, BD Pharmingen). After 4 days, supernatants were harvested and put in $80^{\circ} \mathrm{C}$. Cells were stained with antibodies against cell surface antigens CD4, CD25 (Additional file 1) and $0.125 \mu \mathrm{g}$ of the viability dye 7-AAD (BD Pharmingen) and aquired on a BD FACSLyric ${ }^{\mathrm{TN}}$. Analyses were performed using the proliferation tool in FlowJo version 9.9.4. (Tree Star, Ashland, Oregon). A LEGENDplex bead-based immunoassay was used to analyse the cytokines IL-2, IL-10, IFN $\gamma$ and IL-17A in the supernatants. The assay was performed according to the manufacturer's instructions, acquired on a BD FACSLyric ${ }^{\mathrm{Tm}}$ and analysed using the Legendplex v7.1 software (BioLegend). Limits of quantification were set by the manufacturer as follows: IL-2 $(1.4 \mathrm{pg} / \mathrm{ml}), \mathrm{IL}-10(0.9 \mathrm{pg} / \mathrm{ml}), \mathrm{IFN} \gamma(1.3 \mathrm{pg} / \mathrm{ml})$, IL$17 \mathrm{~A}(2 \mathrm{pg} / \mathrm{ml})$.

\section{Statistics}

Statistical analyses were performed using GraphPad Prism (La Jolla, CA, USA). Wilcoxon signed-rank test was used to calculate the difference between continuous data obtained at baseline (pre) and after 20 weeks (post). The Mann-Whitney $U$ test was used for comparisons of continuous variables, and the fisher's exact test was used for comparisons of nominal variables, between the two groups. A ratio paired t-test was used to compare data from the $\mathrm{T}$ cell proliferation assay between samples collected at baseline (pre) and after 20 weeks (post). A spearman correlation test was used to analyse associations between the frequency of immune cell populations and clinical variables. $P$-values $<0.05$ was considered significant.

\section{Results \\ General physical effects of moderate- to high intensity exercise on health in older adults with RA}

Older adults ( $\geq 65$ years) with RA were randomized to either 20-weeks of exercise intervention $(n=24)$ or control intervention $(n=25)$. There were no significant differences between the groups at baseline. Aerobic capacity, measured as the relative $\mathrm{VO}_{2}$ max, was assessed after 20 weeks of exercise or control intervention to validate the effect of the exercise program. As previously reported for the entire cohort [15], the relative $\mathrm{VO}_{2} \max$ (Fig. 1ab) and leg muscle strength, evaluated as sit-to-stand ability (Table 2), was improved within the intervention group, but not in the control group, in the Gothenburgcohort. There was also a significant difference in $\Delta$ change between groups (Table 2). The intervention group in the Gothenburg-cohort also improved their systolic blood pressure and BMI within the group, whereas there were no significant changes in CRP, N/Lratio, DAS28, CDAI or the HAQ-DI within or between groups (Table 2 and [15]). Still, a significantly higher proportion of the intervention group rated PGIC as improved compared to the control group both in this subanalysis (Table 2) and in the entire cohort [15].

\section{Moderate- to high intensity exercise reduces the frequency of regulatory $T$ cells in older adults with RA}

To study the effect of moderate- to high intensity exercise on anti-inflammatory immune cell populations in older adults with RA, we first assessed the Treg subset in peripheral blood collected before and after 20 weeks of exercise. The frequency of circulatory CD4 + Foxp3 + CD25 + CD127- Tregs was decreased in the intervention group after 20 weeks of exercise (Fig. 2d). Also, the 

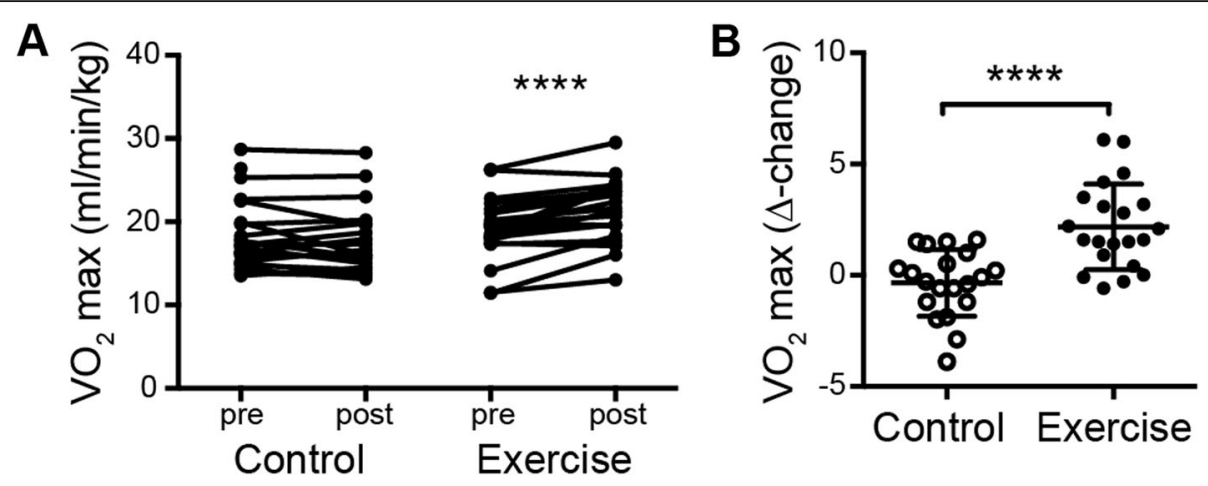

Fig. 1 Changes in respiratory fitness in response to 20 weeks of exercise intervention in older adults with RA. Graphs showing a.the paired measurements (pre and post 20 weeks) of $\mathrm{VO} 2 \mathrm{max}\left(\mathrm{mlO}_{2} / \mathrm{min} / \mathrm{kg}\right)$ and $\mathbf{b}$. the $\Delta$-change value (between pre and post) in the control and exercise intervention group. $P$ values were determined using Wilcoxon signed-rank test comparing data obtained at baseline (pre) and after 20 weeks (post). The Mann-Whitney $U$ test was used for comparison between the two groups. ${ }^{*} p \leq 0.05{ }^{* *} p \leq 0.01{ }^{* * *} p \leq 0.001{ }^{* * *} p \leq 0.0001$

absolute number of Tregs was reduced in the intervention group but not in the control group after 20 weeks of exercise (Fig. 2f). We further analysed whether a reduction in Tregs would influence the proportion of CD25 + Foxp3- effector T cells, but no differences were found within or between the groups (Fig. 2e). The decrease in Tregs did not lead to increased proliferation of total CD4+ T cells (Fig. 2 g-i). There was a significant increase in IL-2 (Fig. 2j) in the supernatants after stimulation with anti-CD3/CD28 for 4 days, when comparing paired patient samples from the intervention group collected before $(n=4)$ and after exercise $(n=4)$ and that had $\Delta$ change in Tregs $<-1$. The same tendency was seen with respect to production in IFN $\gamma$, IL17A or IL10, however without statistical significance. There were no changes in the cell counts of total white blood cells, neutrophils, lymphocytes or the proportions of CD3+ T cells, CD4+ T cells and CD8+ T cells (Table 3). No correlation was found between $\Delta$-change in Tregs and the $\Delta$-change in DAS28, CRP or BMI.

\section{Moderate- to high intensity exercise reduces the frequency of regulatory $B$ cells and serum levels of IL-10 in older adults with RA}

We further assessed the effects of moderate- to high intensity exercise on the regulatory CD24hiCD38hi B cell population (Bregs). We observed a reduced frequency of Bregs after 20 weeks in the exercise intervention group but not in the control group (Fig. 3a). There was no change in the percentage of the total CD19+ population (Table 3). The decrease in regulatory blood lymphocyte populations after 20 weeks of exercise intervention was

Table 2 Variables pre and post intervention

\begin{tabular}{|c|c|c|c|c|c|c|c|}
\hline & \multicolumn{2}{|l|}{ Control } & \multirow{2}{*}{$\begin{array}{l}\text { Pre- } \\
\text { post } \\
\text { p- } \\
\text { value }\end{array}$} & \multicolumn{2}{|l|}{ Exercise } & \multirow{2}{*}{$\begin{array}{l}\text { Pre-post } \\
\text { p-value }\end{array}$} & \multirow{2}{*}{$\begin{array}{l}\Delta- \\
\text { change } \\
\text { p-value }\end{array}$} \\
\hline & $\begin{array}{l}\text { Pre (0 weeks) } \\
n=25\end{array}$ & $\begin{array}{l}\text { Post (20 weeks) } \\
n=24\end{array}$ & & $\begin{array}{l}\text { Pre (0 weeks) } \\
n=24\end{array}$ & $\begin{array}{l}\text { Post (20 weeks) } \\
n=24\end{array}$ & & \\
\hline VO2 $\max \left(\mathrm{mlO}_{2} / \mathrm{min} / \mathrm{kg}\right)$ & $17.2(15.2-19.9)$ & $16(14.8-19-7)$ & 0.45 & $19.3(17.6-21.3)$ & $21.5(19.2-24.2)$ & $<0.0001$ & $<0.0001$ \\
\hline STS (number) & $21(19-26)$ & $24(20-28)$ & 0.02 & $23(21-25)$ & $27(25-28)$ & $<0.0001$ & 0.02 \\
\hline HAQ-DI & $0.50(0.25-0.94)$ & $0.50(0.25-0.97)$ & 0.69 & $0.19(0.0-0.84)$ & $0.13(0.0-0.72)$ & 0.61 & 0.81 \\
\hline $\mathrm{BMI}$ & $27.5(24.8-30.4)$ & $27.6(24.6-29.8)$ & 0.63 & $25.5(21.4-28.0)$ & $24.9(21.3-27.9)$ & 0.005 & 0.053 \\
\hline Systolic BP (mm Hg) & $130(123-145)$ & $128(120-134)$ & 0.24 & $133(130-140)$ & $130(120-134)$ & 0.004 & 0.43 \\
\hline Diastolic BP (mm Hg) & $80(75-80)$ & $80(75-80)$ & 0.92 & $80(76-80)$ & $80(70-84)$ & 0.51 & 0.77 \\
\hline CRP & $2(1-4)$ & $2(1-4)$ & 0.65 & $2.5(1-5.75)$ & $2(1-5.75)$ & 0.36 & 0.73 \\
\hline $\mathrm{N} / \mathrm{L}$ ratio & $1.79(1.31-2.76)$ & $2.09(1.29-2.78)$ & 0.88 & $2.11(1.53-2.96)$ & $2.03(1.38-2.75)$ & 0.80 & 0.56 \\
\hline DAS28 & $2.27(1.56-3.26)$ & $2.12(1.62-2.73)$ & 0.63 & $2.23(1.24-3.22)$ & $2.04(1.50-2.79)$ & 0.47 & 0.88 \\
\hline CDAl & $3.9(2.6-6.6))$ & $3.8(2.0-6.9)$ & 0.30 & $3.2(2.0-7.1)$ & $2.2(0.7-8.0)$ & 0.09 & 0.31 \\
\hline PGIC & - & $3(2.3-3.8)$ & & - & $2(2.0-3.0)$ & & 0.02 \\
\hline
\end{tabular}

Abbrevations: $\mathrm{VO}_{2}$ max maximal oxygen consumption, STS Sit To Stand test, HAQ-DI Health Assessment Questionnaire Disability Index, $B M I$ Body Mass Index, BP blood pressure, CRP C-reactive protein, N/L ratio Neutrophil/lymphocyte ratio, DAS28 Disease Activity Score in 28 joints CDAI Clinical Disease Activity Index, PGIC Patient Global Impression of Change. Values are shown as median \pm IQR. P-values are calculated using the Wilcoxon signed rank test for matched pre- and post samples or the Mann-Whitney test to compare the $\Delta$-change between groups 


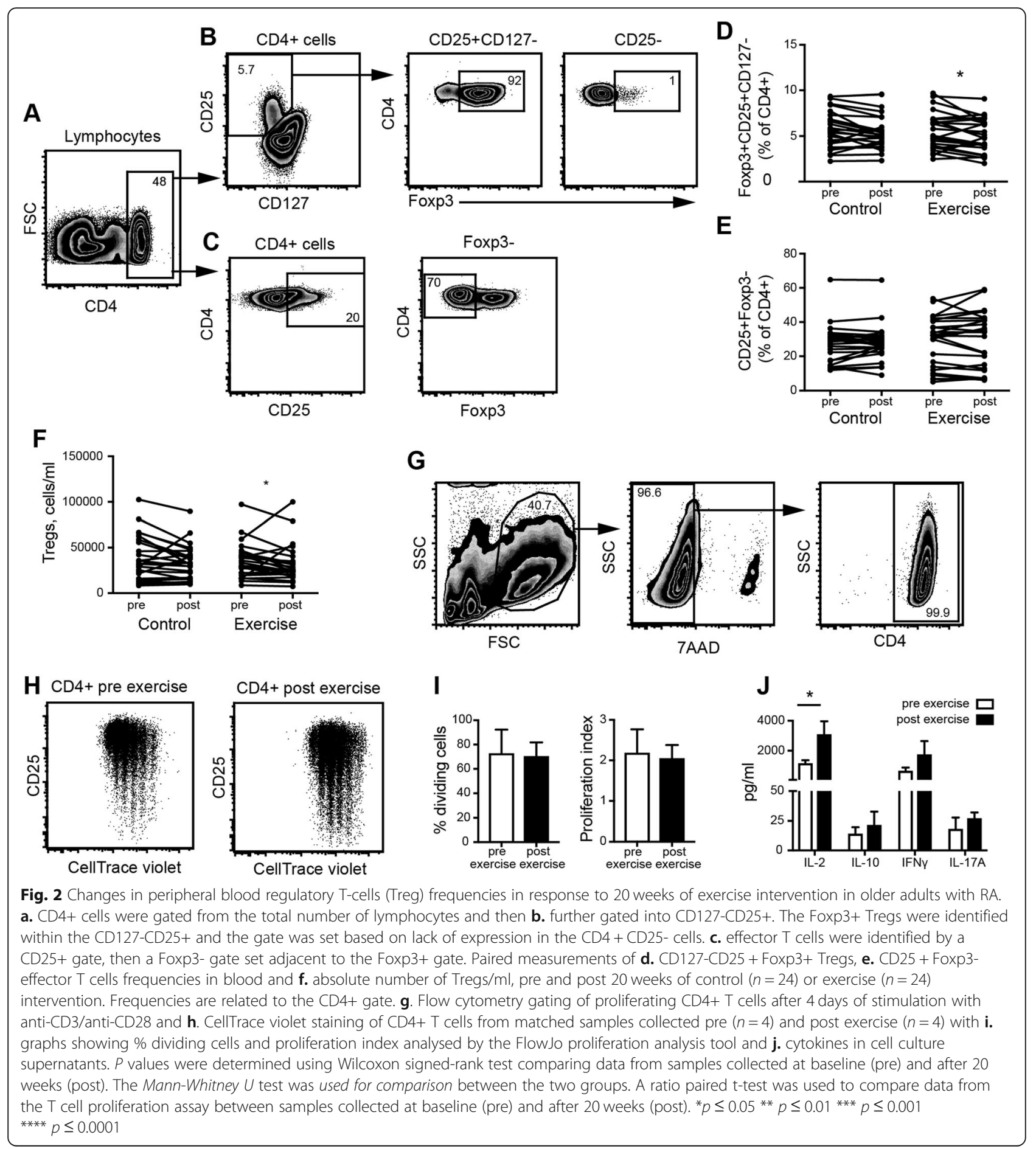

also accompanied by lower levels of IL-10 in plasma in the intervention group but not in the control group (Fig. $3 \mathrm{~b})$. There were no changes in the levels of other measured myokines after exercise intervention (Additional file 3). No correlation was found between $\Delta$ change in Bregs to the $\Delta$-change in DAS28, CRP or BMI. A weak positive correlation was found between $\Delta$ change in IL-10 and $\Delta$-change CRP $(\mathrm{r}=0.365, p=$
0.0116), but no correlation was found between the $\Delta$ change in IL-10 and $\Delta$-change in DAS28 or BMI.

Moderate- to high intensity exercise does not affect the frequency of myeloid derived suppressor cells in older adults with RA

There was no difference within groups or between groups after the intervention period with respect to 
Table 3 Number and frequency of peripheral blood cells pre and post intervention

\begin{tabular}{|c|c|c|c|c|c|c|}
\hline & \multicolumn{3}{|l|}{ Control } & \multicolumn{3}{|l|}{ Exercise } \\
\hline & Pre (0 weeks) & Post (20 weeks) & Pre-post $p$-value & Pre (0 weeks) & Post (20 weeks) & Pre-post $p$-value \\
\hline WBC $\left(\times 10^{6} / \mathrm{ml}\right)\left(\mathrm{mlO}_{2} / \mathrm{min} / \mathrm{kg}\right)$ & $5.3(4.2-6.5)$ & $5.0(4.2-5.7)$ & 0.33 & $5.1(4.3-6.1)$ & $4.7(4.1-5.9)$ & 0.41 \\
\hline Neutrophils $\left(\times 10^{6} / \mathrm{ml}\right)$ & $2.9(2.3-4.0)$ & $2.9(2.4-3.6)$ & 0.58 & $3.0(2.6-3.7)$ & $2.9(2.3-3.6)$ & 0.69 \\
\hline Lymphocytes (× 10\%/ml) & $1.6(1.2-2.0)$ & $1.6(1.1-1.9)$ & 0.31 & $1.7(1.1-2.1)$ & $1.4(1.1-1.9)$ & 0.19 \\
\hline$\%$ CD3 PBMC & $44(37-53)$ & $45(40-55)$ & 0.44 & $50(40-63)$ & $47(40-57)$ & 0.24 \\
\hline$\%$ CD4+ of CD3+ PBMC & $67(51-78)$ & $63(49-76)$ & 0.37 & $63(53-77)$ & $63(56-77)$ & 0.36 \\
\hline$\% \mathrm{CD} 8+$ of $\mathrm{CD} 3+\mathrm{PBMC}$ & $29(16-39)$ & $32(19-44)$ & 0.27 & $27(17-41)$ & $29(19-37)$ & 0.43 \\
\hline \% CD19+ lymphocytes & $9.6(7.5-16)$ & $11(8.4-14)$ & 0.58 & $10(6.1-13)$ & $9.6(5.8-14)$ & 0.57 \\
\hline$\%$ MDSCs of PBMC & $1.7(1.1-2.2)$ & $1.6(1.2-2.7)$ & 0.38 & $2.2(1.2-2.9)$ & $1.9(1.1-3.3)$ & 0.88 \\
\hline
\end{tabular}

Values are shown as median \pm IQR. P-values are calculated using the Wilcoxon signed rank test

frequency of the innate anti-inflammatory MDSCs within the mononuclear cell population (Fig. 3c). We observed the presence of three different cell populations within this gate that could be further distinguished by the surface expression of CD14 and CD15. The proportion of CD15+ MDSCs showed a slight tendency to decrease, although not significant (Fig. 3d).

The effect of moderate- to high intensity exercise on the Treg population differs in women and men

By dividing the participants by sex, we found that females in the intervention group responded to the moderate- to high intensity exercise by a reduced frequency of Tregs whereas males did not. There was no change in Tregs in the control group neither in females nor males (Fig. 4a). There was no sex difference in the response to moderate- to high intensity exercise with respect to Bregs (Fig. 4b) or CD15+ MDSCs (Fig. 4c).

\section{Discussion}

In this report, we show that moderate- to high intensity exercise decreases Tregs and Bregs, as well as the production of IL-10 in older adults with RA, and that the effect on Tregs was only seen in females. To our knowledge this is the first study to demonstrate an effect of moderate- to high intensity exercise intervention on

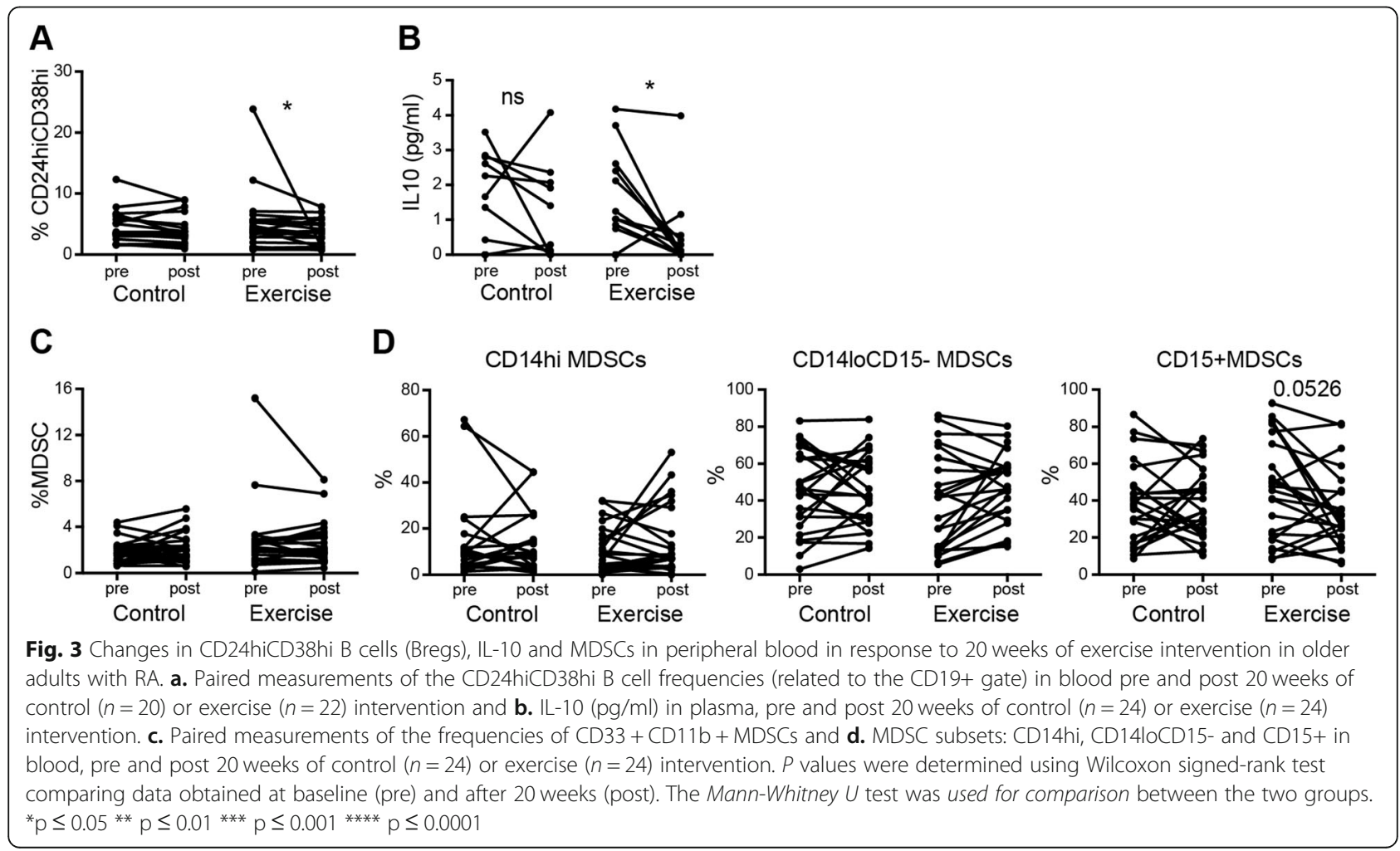




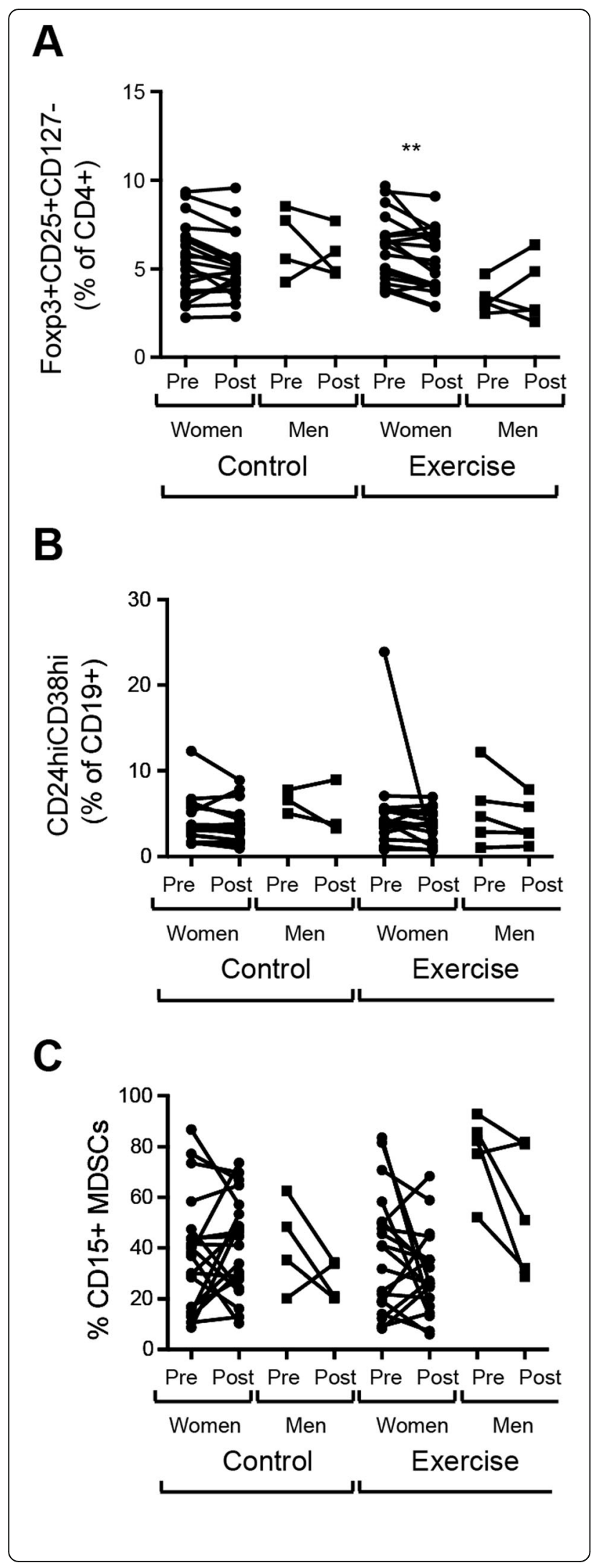

Fig. 4 Changes in regulatory immune cell population frequencies in women and men in response to exercise intervention in older adults with RA. a. Paired measurements of CD127-CD25 + Foxp3+ Treg frequencies b. CD24hiCD38hi B cell frequencies and c. CD15+ MDSC frequencies in blood from women and men (pre and post 20 weeks) in the control $(n=24)$ and exercise $(n=24)$ intervention group respectively. $P$ values were determined using Wilcoxon signed-rank test comparing data obtained at baseline (pre) and after 20 weeks (post). ${ }^{*} p \leq 0.05{ }^{* *} p \leq 0.01{ }^{* * *} p \leq 0.001{ }^{* * * *} p \leq 0.0001$

regulatory cell populations, i.e. peripheral Tregs and Bregs in older adults with RA.

As previously reported, a 20-week moderate- to high intensity exercise intervention clearly improved aerobic capacity as well as leg muscle strength in older adults with RA [15]. In healthy individuals the effects of exercise on the frequencies of Treg in peripheral blood differ between studies, possibly due to factors like age, time of sampling with respect to the time of exercise and the intensity [17-20]. In young elite athletes, a higher $\mathrm{VO}_{2}$ max was associated with an increase in both frequency and number of Tregs [17], while in marathon runners with a mean age of 38 years, there was a sustained postrace decrease in Tregs [18]. The time window between performed exercise and blood sampling needs to be taken into consideration as there are well documented transient responses to acute exercise [18, 19, 21]. However, we believe that more than $24 \mathrm{~h}$ between exercise and blood sampling is enough to reduce the most acute effects [19]. Possible mechanisms for the reduced Treg frequencies following exercise intervention are redistribution from the blood to other tissue [22], reduced peripheral differentiation of Tregs and increased apoptosis $[6,23]$. We did not sample synovial fluid or tissue in this study, which is a limitation as these compartments often contain raised proportion of Tregs [7]. It would have been interesting to know if moderate- to high intensity exercise also reduced Tregs in the joint or if we would have seen a redistribution of Tregs to the joints. In this study, only the female participants in the intervention group responded with decreased Treg frequencies, which could be due to a hormonal influence [17] however there are few males, which is limitation and might influence the results.

Meta-analysis have shown that in RA-patients, the proportion of CD25 + Foxp3 positive Tregs in circulation are lower than in healthy and that lower frequencies are associated with active RA [7]. However, in our study we could not find any signs of increased inflammation or augmented disease after exercise despite lower Treg proportions. The reduction of Tregs after exercise did not seem to affect the proliferative response of $\mathrm{T}$ cells, nor production of IL-10, IFNY and IL17A, despite lower IL-2 consumption. However, there are clear limitations of the 
anti-CD3/anti-CD28 assay, as it can only test bystander suppression by Tregs.

In the intervention group, we found a significant decrease in Bregs and IL-10. In healthy elderly, there is both a numerical and functional deficit of Bregs, associated with increased levels of autoantibodies including rheumatoid factor [9] and in patients with RA the immunosuppressive capacity $[8,24]$ of these cells appear reduced. Previous investigators found that Breg frequencies inversely correlated with inflammation in RA [24, 25]. Our results show that, despite the reduced Breg frequency after moderate- to high intensity exercise this was not associated with increased systemic inflammation as evidenced by stable CRP levels. A limitation is that we did not analyse the CD19+ IL-10+ B cells and therefore subsets of B cells may be missed. Also, the plasma levels of cytokines, including IL-10, were very low to undetectable in some of the samples, which gives less statistical power.

MDSCs, and in particular CD15+ MDSCs accumulate in peripheral blood with age [10]. This subset is almost undetectable in young healthy donors and accumulation of MDSCs may increase the susceptibility to infections, cancer and reduce response to vaccines [11]. However, moderate- to high intensity exercise did not significantly reduce MDSC numbers or frequency, though there was a trend towards an effect.

The lack of effects of exercise on disease activity in the intervention group is unexpected, as several studies have reported benefits of increased physical activity for DAS scores in patients with RA $[13,26]$. This may be explained by the nature of our study cohort. A majority of the participants in this study were in remission or had low disease activity. We speculate that the exercise has a rejuvenating effect, in this case curbing the regulatory arm in order to improve healthy immune function. Initiation of regular exercise can indeed improve innate bactericidal function in older adults with RA [26]. This is in line with the fact that significantly more patients in the intervention group ranked their global impression of health (PGIC) higher at both 20 and 52 weeks compared to the control group, at the same time as there were no differences between the groups with respect to disease activity [15]. These findings suggested the moderate to high intensity exercise is beneficial in older patients with RA, and the reduction of regulatory immune cells in circulation does not influence the long-term outcome of disease.

\section{Conclusion}

The results from this study show that moderate- to high intensity exercise in older adults with RA reduced the serum levels of IL-10 as well as the frequency of Tregs and Bregs, i.e. regulatory adaptive immune cell populations in the circulation. The effects on Tregs were more pronounced in the female participants. This reduction was not accompanied by a change in disease activity score but with an improvement in the patient's own perceived health.

\section{Supplementary information}

Supplementary information accompanies this paper at https://doi.org/10. 1186/s12979-020-00184-y.

\section{Additional file 1 Supplementary Table I. Flow cytometry antibody panels \\ Additional file 2 Supplementary Fig. 2. A. Gating of lymphocytes from PBMC singlets was done in a SSC versus FSC plot. B cells were identified by their expression of CD19+. Regulatory B cells were identified by their expression of CD24 and CD38 and defined as CD24hiCD38hi. Patients that was treated with rituximab $<1$ year before inclusion or during the ongoing study, consequentially lacked B cells and were thus omitted from the flow cytometric $\mathbf{B}$ cell analysis. The total number of patients omitted from the B cell analysis was 6, 2 from the exercise group and 4 from the control group. B. Myeloid derived suppressor cells were gated from the mononuclear cells negative for HLA-DR and CD56. The MDSCs were then identified as being positive for CD33 and CD11b. The three distinct MDSC populations were separated by their expression of CD14 and CD15, namely the CD15+, CD14loCD15- and CD14hi. Identi- cal gates were set for every patient sample pair (pre and post exercise). All phenotypic characterizations were performed using FlowJo version 9.9.4. (TreesStar, Ashland, Oregon).}

Additional file $\mathbf{3}$ Supplementary Fig. 3. The concentrations of BDNF, LIF, TNFa, IL-8, IL1-RA, IL-15. IL-6 and IGF-1 in plasma samples, pre and post 20 weeks of control $(n=24)$ or exercise $(n=24)$ intervention. The lower level of quantification is marked with a dotted line. $P$ values were determined using Wilcoxon signed-rank test comparing data obtained at baseline (pre) and after 20 weeks (post).

\section{Abbreviations}

RA: Rheumatoid arthritis; Tregs: Regulatory T cells; Bregs: Regulatory B cells; MDSCs: Myeloid derived suppressor cells; DAS28: Disease Activity Score 28; CRP: C-reactive protein; PGIC: Patient's global impression of change; $\mathrm{VO}_{2}$ max: Maximal oxygen consumption; CDAl: Clinical disease activity index; HAQ-DI: Health Assessment Questionnaire - Disability Index; PBMC: Peripheral blood mononuclear cells; IL-10: Interleukin 10

\section{Acknowledgements}

We thank Anna Johansson, Marie-Louise Andersson and Anneli Lund, who performed examinations and collected blood samples in Gothenburg.

\section{Authors' contributions}

SEMA, EL, DK, JML, KM and IG designed the study. SEMA, EL, DK, SS, KÖ, MB, EJ contributed to acquisition of data. SEMA, EL, KM and IG analysed and interpreted the data. SEMA and IG drafted the manuscript. SEMA, EL, DK, SS, $K O ̈, M B, E J, J M L, I-L M, K M$ and IG critically revised the manuscript for important intellectual content and approved the final manuscript.

\section{Funding}

This work was supported by the University of Gothenburg Center for Personcentered Care; Health \& Medical Care Committee of the Regional Executive Board [VGFOUREG-66251]; Region Västra Götaland, ALF/LUA at Sahlgrenska University Hospital, [ALFGBG-4636751], the Swedish Rheumatism Association [R-663361], Felix Neubergh's foundation and Norrbacka-eugeniastiftelsen.

Open access funding provided by University of Gothenburg.

Availability of data and materials

The datasets used and analysed during the study are available from the corresponding author on reasonable request.

Ethics approval and consent to participate

The study was approved by the Regional Ethical Review Board in Gothenburg (2014-11-24/790-14, 2015-10-21/T835-15). All study participants 
received both written and oral information about the study and gave their informed, written consent to participate.

\section{Consent for publication}

Not applicable.

\section{Competing interests}

The authors declare that they have no competing interests.

\section{Author details}

'Department of Rheumatology and Inflammation research, Institute of Medicine, The Sahlgrenska Academy, University of Gothenburg, Box 480, 405 30 Göteborg, Sweden. ${ }^{2}$ University of Gothenburg Centre for Person-Centred Care, Gothenburg, Sweden. ${ }^{3}$ Department of Health and Rehabilitation, Institute of Neuroscience and Physiology, The Sahlgrenska Academy, University of Gothenburg, Gothenburg, Sweden. ${ }^{4}$ Department of Molecular and Clinical Medicine, Institute of Medicine, The Sahlgrenska Academy, University of Gothenburg, Gothenburg, Sweden. ${ }^{5}$ Department of Medical Sciences, Clinical Physiology, Uppsala University, Uppsala, Sweden. ${ }^{6}$ MRC-ARUK Centre for Musculoskeletal Ageing Research, Institute of Inflammation and Ageing, University of Birmingham, Birmingham, UK.

Received: 17 January 2020 Accepted: 7 May 2020

Published online: 16 May 2020

\section{References}

1. Crowson CS, Liang KP, Therneau TM, Kremers HM, Gabriel SE. Could accelerated aging explain the excess mortality in patients with seropositive rheumatoid arthritis? Arthritis Rheum. 2010;62(2):378-82.

2. Duggal NA, Niemiro G, Harridge SDR, Simpson RJ, Lord JM. Can physical activity ameliorate immunosenescence and thereby reduce age-related multi-morbidity? Nat Rev Immunol. 2019;19(9):563-72.

3. Jagger A, Shimojima Y, Goronzy JJ, Weyand CM. Regulatory T cells and the immune aging process: a mini-review. Gerontology. 2014;60(2):130-7.

4. Kugel CH, Douglass SM, Webster MR, Kaur A, Liu Q, Yin X, et al. Age correlates with response to anti-PD1, reflecting age-related differences in Intratumoral effector and regulatory T-cell populations. Clin Cancer Res. 2018;24(21):5347

5. Lages CS, Suffia I, Velilla PA, Huang B, Warshaw G, Hildeman DA, et al. Functional regulatory $T$ cells accumulate in aged hosts and promote chronic infectious disease reactivation. J Immunol. 2008;181(3):1835-48.

6. Vukmanovic-Stejic M, Zhang Y, Cook JE, Fletcher JM, McQuaid A, Masters JE, et al. Human CD4+ CD25hi Foxp3+ regulatory T cells are derived by rapid turnover of memory populations in vivo. J Clin Invest. 2006;116(9):2423-33.

7. Morita T, Shima Y, Wing JB, Sakaguchi S, Ogata A, Kumanogoh A. The proportion of regulatory $T$ cells in patients with rheumatoid arthritis: a meta-analysis. PLoS One. 2016:11(9):e0162306.

8. Flores-Borja F, Bosma A, Ng D, Reddy V, Ehrenstein MR, Isenberg DA, et al. CD19+CD24hiCD38hi B cells maintain regulatory T cells while limiting TH1 and TH17 differentiation. Sci Transl Med. 2013;5(173):173ra23.

9. Duggal NA, Upton J, Phillips AC, Sapey E, Lord JM. An age-related numerical and functional deficit in CD19+ CD24hiCD38hi B cells is associated with an increase in systemic autoimmunity. Aging Cell. 2013;12(5):873-81.

10. Verschoor CP, Johnstone J, Millar J, Dorrington MG, Habibagahi M, Lelic A et al. Blood CD33(+)HLA-DR(-) myeloid-derived suppressor cells are increased with age and a history of cancer. J Leukoc Biol. 2013;93(4):633-7.

11. Veglia F, Perego M, Gabrilovich D. Myeloid-derived suppressor cells coming of age. Nat Immunol. 2018;19(2):108-19.

12. Simpson RJ, Lowder TW, Spielmann G, Bigley AB, LaVoy EC, Kunz H. Exercise and the aging immune system. Ageing Res Rev. 2012;11(3):404-20.

13. Metsios GS, Stavropoulos-Kalinoglou A, Kitas GD. The role of exercise in the management of rheumatoid arthritis. Expert Rev Clin Immunol. 2015;11(10): 1121-30.

14. Gleeson M, Bishop NC, Stensel DJ, Lindley MR, Mastana SS, Nimmo MA. The anti-inflammatory effects of exercise: mechanisms and implications for the prevention and treatment of disease. Nat Rev Immunol. 2011;11(9):607-15.

15. Lange E, Kucharski D, Svedlund S, Svensson K, Bertholds G, Gjertsson I, et al. Effects of aerobic and resistance exercise in older adults with rheumatoid arthritis: a randomized controlled trial. Arthritis Care Res (Hoboken). 2019: 71(1):61-70
16. Kucharski D, Lange E, Ross AB, Svedlund S, Feldthusen C, Onnheim K, et al Moderate-to-high intensity exercise with person-centered guidance influences fatigue in older adults with rheumatoid arthritis. Rheumatol Int. 2019:39(9):1585-94.

17. Weinhold M, Shimabukuro-Vornhagen A, Franke A, Theurich S, Wahl P, Hallek $M$, et al. Physical exercise modulates the homeostasis of human regulatory T cells. J Allergy Clin Immunol. 2016;137(5):1607-10 e8.

18. Perry C, Pick M, Bdolach N, Hazan-Halevi I, Kay S, Berr I, et al. Endurance exercise diverts the balance between Th17 cells and regulatory T cells. PLoS One. 2013;8(10):e74722.

19. Clifford T, Wood MJ, Stocks P, Howatson G, Stevenson EJ, Hilkens CMU. Tregulatory cells exhibit a biphasic response to prolonged endurance exercise in humans. Eur J Appl Physiol. 2017;117(8):1727-37.

20. Minuzzi LG, Rama L, Bishop NC, Rosado F, Martinho A, Paiva A, et al. Lifelong training improves anti-inflammatory environment and maintains the number of regulatory T cells in masters athletes. Eur J Appl Physiol. 2017;117(6):1131-40

21. Perry C, Herishanu Y, Hazan-Halevy I, Kay S, Bdolach N, Naparstek E, et al. Reciprocal changes in regulatory T cells and Th17 helper cells induced by exercise in patients with chronic lymphocytic leukemia. Leuk Lymphoma. 2012;53(9):1807-10.

22. Lowder T, Dugger K, Deshane J, Estell K, Schwiebert LM. Repeated bouts of aerobic exercise enhance regulatory $T$ cell responses in a murine asthma model. Brain Behav Immun. 2010;24(1):153-9.

23. Pierson W, Cauwe B, Policheni A, Schlenner SM, Franckaert D, Berges J, et al. Antiapoptotic Mcl-1 is critical for the survival and niche-filling capacity of Foxp3+ regulatory T cells. Nat Immunol. 2013;14(9):959-65.

24. Daien Cl, Gailhac S, Mura T, Audo R, Combe B, Hahne M, et al. Regulatory $B 10$ cells are decreased in patients with rheumatoid arthritis and are inversely correlated with disease activity. Arthritis Rheumatol. 2014;66(8): 2037-46.

25. Ma L, Liu B, Jiang $Z$, Jiang $Y$. Reduced numbers of regulatory $B$ cells are negatively correlated with disease activity in patients with new-onset rheumatoid arthritis. Clin Rheumatol. 2014;33(2):187-95.

26. Bartlett DB, Willis LH, Slentz CA, Hoselton A, Kelly L, Huebner JL, et al. Ten weeks of high-intensity interval walk training is associated with reduced disease activity and improved innate immune function in older adults with rheumatoid arthritis: a pilot study. Arthritis Res Ther. 2018;20(1):127.

\section{Publisher's Note}

Springer Nature remains neutral with regard to jurisdictional claims in published maps and institutional affiliations.

Ready to submit your research? Choose BMC and benefit from:

- fast, convenient online submission

- thorough peer review by experienced researchers in your field

- rapid publication on acceptance

- support for research data, including large and complex data types

- gold Open Access which fosters wider collaboration and increased citations

- maximum visibility for your research: over $100 \mathrm{M}$ website views per year

At BMC, research is always in progress.

Learn more biomedcentral.com/submissions 